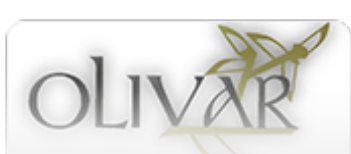

Olivar

ISSN: 1852-4478

publicaciones@fahce.unlp.edu.ar

Universidad Nacional de La Plata

Argentina

\title{
¿Y si nos reímos? La comedia cinematográfica tras el fin de ETA
}

\author{
Barrenetxea Marañón, Igor \\ ¿Y si nos reímos? La comedia cinematográfica tras el fin de ETA \\ Olivar, vol. 19, núm. 30, 2019 \\ Universidad Nacional de La Plata, Argentina \\ DOI: https://doi.org/10.24215/18524478e064
}

Esta obra está bajo una Licencia Creative Commons Atribución-NoComercial-Compartirlgual 4.0 Internacional. 
Artículos

\section{¿Y si nos reímos? La comedia cinematográfica tras el fin de ETA}

And if we laugh ourselves? The cinematographic comedy after the end of ETA

Igor Barrenetxea Marañón

DOI: https://doi.org/10.24215/18524478e064

Universidad Internacional de La Rioja, España

\section{Resumen:}

Aunque se han rodado más de un centenar de películas sobre ETA, salvo una, todas han sido retratos amargos del drama de su violencia y terror. No será hasta su anuncio del fin de la vía armada, en 2011, cuando se abriría una senda inusitada a la hora de tratar la influencia del terrorismo en la sociedad española con una serie de películas de humor como son: 8 apellidos vascos (2014), Negociador (2014) y Fe de etarras (2017). Este artículo analiza las claves de estos filmes y la necesidad que cobra toda sociedad de encarar ciertas crudas realidades mediante la sátira y la comedia.

Palabras clave: Cine, ETA, Cobeaga, San José, Comedía.

\section{ABstRACT:}

Even though more than a hundred films have been shot on ETA, all but one have been bitter pictures of the drama caused by their violence and terror. It would not be until after their announcement to end their armed struggle in 2011 that an unusual path to deal with the influence of terrorism on Spanish society would open, with a series of humor films such as 8 apellidos vascos (2014), Negociador (2014) and Fe de etarras (Bomb scared) (2017). This article analyzes the keys of these films and the necessity that every society develops to face certain crude realities by means of satire and comedy.

KEYWORDs: Cinema, ETA, Cobeaga, San José, Comedy.

La risa tiene algo de venganza contra la realidad y creo que es un mecanismo de defensa después de todo lo que hemos sufrido, distinguiendo muy bien lo que he podido sufrir yo como ciudadano y lo que han sufrido las víctimas que es completamente diferente. No se cierran heridas, pero libera.

Rocío García (2014)

\section{INTRODUCCIÓN}

El 20 de octubre de 2011 ETA (Euskadi Ta Askatasuna, País Vasco y Libertad) publicaba un comunicado en el que ponía fin a más de cinco décadas de terrorismo vasco en España (Aizpeolea, 2011). Fue un punto de inflexión muy importante, tanto para la sociedad vasca como para la española. Y si bien la organización terrorista no se disolvería hasta 2018, un aspecto importante había cambiado tras más de 845 asesinatos, miles de amenazados y víctimas. ETA, que había nacido en 1959 y cometido su primer asesinato en 1968, ya no era una temible sombra que atenazaba la garganta y los corazones de la gente, con sus amenazas y atentados. Había sido más de medio siglo de terrible andadura (López Romo, 2015, p. 149). Quedaba saber cómo se iba a enfrentar la sociedad a este drama y a sus heridas (las víctimas). Y, sin duda, tanto el cine como la literatura iban a tener mucho que decir a este respecto.

En el caso del cine, ETA ha sido retratada innumerables veces, tanto desde la ficción como desde el documental, en más de un centenar de producciones, incluyendo cortometrajes, con mayor o menor éxito. Sin embargo, en una sola ocasión antes del fin de ETA se había intentado desdramatizar su terrible realidad con una comedia. Fue el caso del filme Cómo levantar 1.000 kilos (1991), de Antonio Hernández, que resultó un auténtico fracaso tanto artístico como de público (De Pablo, 2017, pp. 307-310). 
Fue la televisión quien suplió la ausencia del recurso al humor en el cine, a partir de 2003, con el programa Vaya semanita, de ETB2 (con Borja Cobeaga y Diego San Sebastián como guionistas), aunque también hubo otros que se sumaron a esta vía satírica, como Las noticias del guiñol (Canal + y, más tarde, Cuatro), en el que se incluyó a un personaje con txapela y tapado con capucha negra, Polónia y Homo Zapping News, cuyos sketches traerían bastante polémica (San José, 2008, pp. 239-250; Carcajosa Virino, 2010, pp. 205-207).

A todo ello hay que sumar que la cinematografía sobre ETA nunca había sido, salvo excepciones, bien recibida, ya sea por su tratamiento temático, su baja calidad o por esa reticencia de acudir a las salas de cine ante un tema dramático, que estaba tan presente en la realidad española (Roldán, 2001). Pero no hay duda de que el séptimo arte contribuye a radiografiar ciertos aspectos de la sociedad, revelando idiosincrasias y realidades. Asimismo, también refleja cómo una sociedad se puede retratar a sí misma y el modo en el que desdramatiza y, por lo mismo, desacraliza ciertos hechos, como fórmula para curar heridas y confrontar traumas, en un tiempo tan terrible como habían sido, en este caso, tantas décadas de terrorismo (Ferro, 1995; Rosenstone, 2014). Si Imanol Uribe, con tres de sus películas, creó la denominada trilogía [trágica] vasca (Barrenetxea, 2003) ${ }^{1}$, en la década de los 70 y 80, a las que más adelante se unirían Días contados (1990) y Lejos del mar (2015), cabría valorar que el guionista Borja Cobeaga hizo lo propio con esta trilogía [cómica] vasca, compuesta por los filmes Ocho apellidos vascos (2014), Negociador (2014) y Fe de etarras (2017). Aunque solo dirigió las dos últimas, fue el autor del guión de las tres (junto a Diego San José en la primera y tercera), rompiendo así una larga travesía por el desierto en lo que respecta al uso del humor en este tema.

Pero, ¿qué aportaciones puede tener el humor a un marco tan duro y sufrido como el de ETA? Tanto el genial director y actor Charles Chaplin con El gran dictador (1941) como Roberto Benigni con La vida es bella (1998), mostraron que era posible tratar temas tan oscuros como el nazismo y el Holocausto con un sentido del humor y la ironía adecuados para desnudar los fanatismos o dejar en evidencia la realidad absurda y temible que los totalitarismos dejan a su paso. ${ }^{2}$ Cobeaga y San José quizás no pretendían tanto, pero sí han ayudado a conferir una nueva visión de cómo mostrar el fenómeno de ETA, alejándose de esa iconografía heroica que ella misma cultivó durante el franquismo (Calleja, 2015, p. 58).

\section{2. (IN)FELICES PARA SIEMPRE}

El 14 de marzo de 2014 se estrenaba en los cines españoles Ocho apellidos vascos, dirigida por Emilio MartínezLázaro, quien ya había tenido éxito con otras películas de humor, como Los peores años de nuestra vida (1994) o El otro lado de la cama (2002) y su continuación, aunque también había rodado películas dramáticas de éxito, como Las 13 rosas (2007). Su único acercamiento al tema de ETA, aunque sería tangencialmente, había sido en la fallida La voz de su amo (2000) (De Pablo, 2017, pp. 239-242). Sin embargo, Ocho apellidos vascos fue enseguida catapultada al éxito, convirtiéndose en la película más taquillera de la historia del cine español. Su éxito se hizo viral, tanto en Euskadi como en el resto de la península, consiguiendo la cifra récord de más de nueve millones de espectadores (Mecd).

La fórmula utilizada era la de contraponer los clichés y estereotipos de la identidad andaluza frente a la vasca, incidiendo sobre todo más en la vinculada a la izquierda abertzale. No había duda de que la intención era desdramatizar (Barrenetxea y Viadero, 2017, p. 267) este escenario en el que el dolor de las víctimas y la táctica de la espiral de terror venían a estar muy presentes (Mate, 2008; Rodríguez, 2015; Castells y Rivera, 2015; Martínez Álvarez, 2017). Aunque la elección de Clara Lago (Amaia) como prototipo de chica abertzale, al ser madrileña, pudo traer su debate, su quimica con el humorista Dani Rovira (Rafa) dio el contraste perfecto para lo que se buscaba. Por el contrario, nadie podía objetar nada a la figura del padre de Clara, Karra Elejalde (Koldo), reconocido actor vasco.

En el filme, el flechazo que siente Rafa, el modelo andaluz (chistoso y abierto), respecto a Amaia, prototipo de mujer vasca (nacionalista radical y con mucho carácter), generará una serie de situaciones entre cómicas 
e imposibles, que ironizan sobre la visión que tienen los españoles del sur de los vascos tópicos. ${ }^{3}$ La enorme repercusión de esta caricatura identitaria solo puede explicarse en el contexto en el que surgió, una España sin ETA (o, por lo menos, comprometida a dejar de lado la vía del terror).

Ocho apellidos vascos retrata bien esa codificación exagerada que se ha hecho de la identidad vasca, no para vulgarizarla, ni mucho menos, sino para mostrarnos lo terapéutico que es reírse de ciertos clichés culturales y, en este caso sí, dejar en evidencia ciertos elementos de la idiosincrasia abertzale y su escenografía vinculada a ETA a través de la kale borroka (lucha callejera ${ }^{4}$ ) y de su identificación con ella. El filme no trata a la banda terrorista directamente (como sí sucederá en las dos películas siguientes), aunque se la menciona y alude, centrándose, sobre todo, en su entorno y los ambientes abertzales. De hecho, al llevar a cabo su propósito de una forma tan suave, tan poco política, ni tan siquiera hubo duras críticas, en general, por parte de los medios abertzales, ni tampoco algunos colectivos de víctimas del terrorismo se sintieron incómodas con el resultado (De Pablo, 2017, pp. 432-433).

Retomando el hilo de la trama, una suerte de acontecimientos llevarán a Rafa, el protagonista, no solo a viajar de Sevilla a Euskadi, a un pueblecito pesquero, sino a tener que hacerse pasar por el novio de Amaia, para evitar que el padre de ella no se entere de que ha roto su verdadero compromiso. Para proceder al engaño, Rafa encontrará incluso la comprensión y amistad de Merche, viuda de un guardia civil, que ahora vive afincada en Euskadi, y que se hace pasar por su madre. Por supuesto, Rafa, al interpretar el papel del futuro yerno de Koldo, ha de imbuirse con esos rasgos considerados propiamentevascos (incluyendo algunos específicos de la izquierda nacionalista radical próxima a ETA): portar la palestina, imitar un acento euskaldún, el inventarse sus míticos ocho apellidos vascos (en realidad, siete, porque uno, Clemente, no lo es), intentar hace creer que sabe euskera, participar de la kale borroka y, por supuesto, el degustar la gastronomía vasca con una pantagruélica cena, así como mostrar su afición por los deportes autóctonos (como jugar a la pelota), etc.

Martínez-Lázaro supo aprovecharse de un sutil y fresco guion para dirigir una chispeante y acertada comedia. En ella, además, nos ayuda a comprender esa imagen falseada que se tiene de Euskadi ${ }^{5}$, pero también el efecto pernicioso que ha tenido ETA, con sus prejuicios hacia lo vasco, algo que queda muy latente en los momentos en los que los amigos de Rafa creen que hasta el bolso de Amaia es explosivo, o suponer que forma parte de un comando (talde), o cuando acuden a su boda disfrazados de vascos, con el fin de rescatarle ante la creencia de que le han secuestrado. Al cierre, el hecho de que Koldo descubra que Merche, la que cree madre de Rafa, tras acostarse con ella, ha sido la mujer de un guardia civil o que sea la propia Amaia la que vaya a buscar a Rafa hasta Sevilla, tras la fallida boda, no es sino una apuesta singularmente positiva y seudorromántica en la que se desvela que incluso los aparentemente contrarios se aman. El final feliz, asimismo, ayuda a concitar esa atracción de los aparentemente contrarios.

El acierto de la trama y de la realización viene señalado por esa conjunción de elementos representativos e icónicos que acaban siendo objeto de burla. Por ejemplo, en un momento dado, Rafa, con su falso acento vasco y su atuendo de integrante de Jarrai (la organización juvenil abertzale), canta "Euskadi tiene un color especial", una versión de "Sevilla tiene un color especial”, no tanto como una burla, sino como una forma de expresar que todos nos dejamos llevar por el cariño a la tierra, pero que esto, en la exageración, lleva al perverso fanatismo generador de odios y rencores.

La película, además, lograría varios premios y nominaciones en los premios Goya, consiguiendo ganar Dani Rovira en la categoría de mejor actor revelación, y Carmen Machi y Karra Elejalde como actores de reparto. Rovira y Elejalde también obtendrían sendos premios del Círculo de Escritores Cinematográficos y el Fotogramas de Plata como mejor película según el público. Sería nominada en cuatro categorías en los Premios Feroz, por sus intérpretes y como mejor tráiler, sin ganar ninguno (Filmaffinity).

Cabría, además, destacar las consecuencias positivas que trajo consigo la gran aceptación del filme. En primer lugar, daría lugar a una continuación, esta vez, con el tema catalán como eje principal, Ocho apellidos catalanes (2015), aunque sin tanta repercusión ni acierto en el tono paródico. Después en Cuerpo de élite (2016), de Joaquín Mazón (que, más tarde, acabaría convirtiéndose en serie), debido a la amenaza de un 
atentado terrorista, el ministro del Interior reúne a lo más granado de los cuerpos policiales españoles, un ertzaina (policía vasco), un mosso (policía catalán), un legionario, un policía de Movilidad y una guardia civil.

La trama se aprovecha de los consabidos estereotipos de los integrantes de cada cuerpo. Aunque no aportó nada destacable al género y algunos momentos cómicos son un tanto burdos, sí quedaba claro que se buscaba salir de ese dramatismo a la hora de mirar nuestro presente, utilizando aquellos elementos que describen la pluralidad española en tono divertido. Además, en relación al tema que nos ocupa, el filme se permite el lujo de parodiar el final de ETA con viejos clichés. La escena trascurre, cómo no, en un caserío vasco, en el que un antiguo etarra, Antxon, ha visto cómo cerraba su empresa y quería deshacerse de la casa, la cual contiene todo un arsenal de armas y hasta un zulo (para ocultar a los secuestrados). Para rizar el rizo, este personaje ha tenido un tórrido romance homosexual con el ertzaina, contribuyendo así a mostrar a una ETA diferente.

\section{Palabra de vasco}

Negociador (2014), es una película inspirada libremente en las conversaciones secretas que sostuvo el líder socialista Jesús Eguiguren con ETA, en Ginebra (Suiza). Arropado por el éxito cosechado por Ocho apellidos vascos (2014), Cobeaga se encargaría de su realización. Este contaba con varios cortos en su haber, además de dos largometrajes anteriores, ambos comedias, que tuvieron su buena acogida: Pagafantas (2009) y No controles (2010).

Posteriormente, en un año muy intenso para Cobeaga como guionista y director, también rodaría el mediometraje Aupa Josu (2014), junto a Diego San José, en el que ambos proponían una imaginativa historia en la que un consejero de Agricultura se ofrecía a poner fin a ETA si se le concedía la consejería de Interior del Gobierno vasco (De Pablo, 2017, pp. 430-431).

Por su parte, la original propuesta de Negociador viene ligada a ofrecer un punto de vista muy diferente a un tema polémico y controvertido como fueron las negociaciones con ETA en 2005 y 2006, para poner fin a su actividad terrorista (Aizpeolea, 2007).

Entre el elenco de actores se encontraban Ramón Barea (Manu), uno de los más reputados de la escena vasca, encarnando a Eguiguren. Oscar Ladoire sería Alfredo Pérez Rubalcaba (Alberto) -portavoz del Gobierno socialista en esos momentos-, y para los dos jefes de ETA contó con Josean Bengoetxea (Jokin), para hacer de Josu Ternera, y Carlos Areces de Xabier López Peña (Patxi), conocido como Thierry.

El filme, más que una comedia al uso, aunque eso no evita recoger anécdotas graciosas reales, tiene aires de farsa contenida. El hecho es evidente cuando se les cambian los auténticos nombres a los protagonistas por otros ficticios, aunque físicamente mantienen el parecido con los personajes a los que encarnan. Con ello, parece que se indica veladamente que la trama no pretende ser verídica, sino más bien mostrar, en una sutil sátira, la importancia del factor humano en los procesos históricos, incluso en las particularidades de la situación vasca y, fundamentalmente, subraya la relevancia que comporta el hablar (a pesar de que el lenguaje se puede convertir en un lodazal), como la única manera de entenderse y comunicarse.

En este caso, el protagonista, Manu, se encontrará con Jokin en un Centro de Mediación, un hotel, en un lugar sin identificar (en Francia). Nadie debe saber nada del asunto, para que no le explote al Gobierno central en las manos (Calvo Soler, 2009; Sordo Estella, 2017). ${ }^{6}$

Tras un largo viaje, en el centro donde se van a desarrollar las conversaciones, le reciben James, el mediador anglosajón, y Sophie, la intérprete, quienes le confunden con el representante de ETA: "Por ir arrugado parezco un etarra, ¿no?”. No hay duda de que simboliza bien cómo las apariencias son siempre engañosas. Sin embargo, el proceso de diálogo (y/o negociación) es más complicado de lo que parece a simple vista. En primer lugar, Manu indica que van a tratar el tema de la violencia, mientras que para Jokin primero es el conflicto (Molina, 2015, pp. 181-223; Fernández Soldevilla, 2015, pp. 213-240). ${ }^{7}$ En segundo lugar, deben ponerse de acuerdo en el uso de una terminología que signifique lo mismo. 
De hecho, la diferencia de acepciones, a veces, se torna imposible de diferenciar desde fuera ya que, por ejemplo, tanto pueblo vasco como Euskal Herria significan lo mismo en inglés. Aunque su carácter político sea tan distinto para Manu y para Jokin, como no saben cómo salir de ese atolladero acaban por aceptar que signifique lo mismo.

Tal y como señalaba el mismo director: "Aquí hemos sido capaces de retorcer el lenguaje hasta extremos increíbles" (García, 2014). Algo que aprovecha y queda muy bien reflejado en las conversaciones que se dan en la mesa de diálogo y fuera de ella.

Con todo, Manu hallará desahogo a su frustración, ante el enquistamiento de las conversaciones, con una prostituta latinoamericana a la que intenta explicarle, infructuosamente, la cuestión. Y cuando señala que el territorio vasco tiene varios nombres (País Vasco, Euskal Herria, Euskadi o Vascongadas), aunque no significan lo mismo, ella le cuenta una anécdota, señalando que, al final, no importa cómo se llame algo, sino evitar discutir sobre ello. Lo que le dará la clave para entenderse con Jokin.

Asimismo, los burdos intentos de Manu por simpatizar con Jokin tienen su gracia (como cuando sale a correr en traje de baño), queriendo romper esa distancia que no ayuda en el diálogo entre las partes. Pero tampoco Jokin es perfecto. De hecho, no tiene empacho en arrogarse la autoría de una bonita frase que ha escuchado en una película la noche anterior, aunque permutando un término, negándose a reconocer su procedencia.

Dice así: "para hablar siempre hay tiempo, pero para olvidar nunca hay suficiente". Jokin cambiará "olvidar" por "perdonar". Un guiño irónico al hecho de cómo acomodamos el lenguaje (y los conceptos que lo integran) a los tiempos políticos y sus necesidades.

Por fin, cuando parece que ya están a punto de firmar el documento que puede llevar a un acuerdo, la traductora, Sophie, no aparece y no pueden llevar a buen término la firma. Frustrados, Manu y Jokin reconocerán que necesitan resolver el acuerdo por el que se han reunido porque no tienen ni fondos para pagarse una ronda, debido a que no pueden utilizar sus tarjetas de crédito (un hecho verídico).

Y cuando, ya, Manu y Jokin se entienden viendo la televisión y saqueando el minibar del hotel, una llamada hace que Jokin se vaya y, unas semanas más tarde, ocupa Patxi su lugar, cuyo carácter es imperativo e inestable, deshaciendo su labor de hacerse entender que tanto les había costado componer a Manu y a Jokin.

La centralidad de la trama principal impide, tal vez, ahondar más en otros aspectos secundarios de interés, como es la presencia de los escoltas por parte de Manu o Alberto, donde uno de ellos muestra su preocupación de quedarse sin trabajo si se acaba la violencia. Si bien, su presencia muestra la cruda verdad y la sombra de la amenaza de ETA sobre la sociedad en esos años (incluso, cuando un camarero confunde a Patxi con el escolta de Manu, cuando salen a comer fuera). También se perfila ese ambiente amargo y despectivo existente en ciertos lugares, en los pueblos y diversas localidades, contra aquellos vascos, como Manu, señalados por ETA y la izquierda abertzale como enemigos del pueblo, a pesar de haber crecido y vivido con ellos.

Sin embargo, el diálogo permitirá una cierta esperanza, por lo que el filme acaba en una gran elipsis, con Manu comiendo solo en un bar que suele frecuentar en San Sebastián, pero esta vez sus amigos de la infancia, que le ignoraban, ahora le saludan, al entender que ha hecho todo lo posible por alcanzar la paz. Eso solo se puede explicar por el deseo reinante en el mundo abertzale de que se acabe con la violencia (Fernández Soldevilla y López Romo, 2012). ${ }^{8}$

Tanto el metraje, apenas una hora larga de duración, como la realización (apenas unas cuentas escenas exteriores), llevan a considerar que Negociador es una película menor, pero muy importante en la cinematografía, por atreverse con tanto acierto a tratar una cuestión no siempre fácil de llevar a la pantalla. El equilibrio entre realidad y ficción es sutil, lo que permite convertirlo en una aguda sátira, que insiste en mostrar que imperan más los factores humanos (y emocionales) que los ideológicos en el entendimiento (o no) de las personas. El fanatismo de Patxi y su carácter imperativo, frente al más dialogante Jokin, nos muestra, con todo, la faz de esas dos ETAs (la más encastillada, y aquella que buscó entenderse con las autoridades) (Domínguez, 2017, pp. 34-38; Arregui, 2015, pp. 107-118). Sin olvidarse de que su principal recurso es la 
amenaza y la violencia cuando los términos del diálogo no se ajustan a lo que quiere, como cuando Manu teme por su vida tras fracasar las negociaciones (aunque solo es un susto).

Además, está el recordatorio a las víctimas, cuando le vemos ponerse una corbata negra a Manu, que significa otro asesinato por parte de la banda terrorista.

Queda claro que el tópico de que la palabra de un vasco no se rompe se deshace, en un marco en el que el lenguaje es tan confuso, es un bosque que hay que ir despejando de sus entramados para permitir atravesarlo, en su simbolismo metafórico, pero que, al final, no sirve de nada ante los intransigentes de turno, cuya arrogancia y vanidad es tan fuerte que deriva en hacer fracasar cualquier intento de paz o acuerdo para poner fin a la violencia. Curiosamente, su cierre es muy intuitivo, porque precisamente enmarca muy bien el proceso en el que se puso fin a ETA, no mediante un diálogo, sino mediante la encarcelación de sus principales dirigentes y su derrota total y absoluta. Así, debido a esta conjunción de factores, tanto estilísticos como sociales, la película obtendría el Premio Irizar al cine vasco (2014) y los premios Feroz a mejor comedia, siendo nominado el guion, al igual que en los premios Goya de 2016 (Filmaffinity).

\section{AÚpa España}

Como se ha ido viendo, el tremendo éxito de Ocho apellidos vascos (2014) permitió que Borja Cobeaga pudiese alumbrar Negociador (2014), sin embargo, debemos insistir en que fue avalado por el contexto y por la buena aceptación de su primera propuesta. Porque cuando anunció su idea de rodar $F e$ de etarras, en 2011, no prosperó. En ese momento todavía la alargada sombra de ETA pesaba entre los productores. Aunque la idea no fue mal recibida o, al menos, no generó una reacción negativa, a pesar del optimismo de Cobeaga, este no pudo llevarla a buen puerto hasta unos años más tarde (De Pablo, 2017, p. 310; Koch, 2017), gracias a la plataforma Netflix, no sin cierta polémica por su agresiva campaña en la que se tachaba la frase "Yo soy español” (Belategui, 2017). ${ }^{9}$ Ocho apellidos vascos se ambientaba, principalmente, en Euskadi, y Negociador en el País Vasco francés. En el primer caso se procedía a llevar a cabo una comedia ácida sobre la identidad abertzale y en el segundo se mostraba la complejidad a la hora de debatir con ETA su final. En esta tercera entrega, Cobeaga se propone algo más arriesgado. Presenta la historia de un comando de ETA: ¿el último comando operativo de la banda antes de poner fin a su andadura?

El filme, con un título ya irónico ${ }^{10}$, se contextualizaba en el verano de 2010, antes de la renuncia de ETA a la vía armada, y justo cuando la selección española de fútbol lograría alzar la Copa del Mundo. En una ciudad española de provincias, Martín (Javier Cámara) dirige un comando con la intención de orquestar una "acción" (ekintza), o lo que es lo mismo, un atentado, para evitar que los sectores más pacifistas de la banda puedan poner fin a su andadura.

En este sentido, como en Negociador, nos plantea la existencia de dos ETAs, algo que rara vez se ha visto en el cine. Una totalmente empeñada en morir con las armas en la mano, y otra que está dispuesta a reconocer que ya no se puede seguir así. De hecho, pocas películas han retratado el interior de ETA, destacándose tan solo dos: El viaje de Arián (2000), de Eduard Bosch y, con matices, Dias Contados (1990), de Imanol Uribe. No solo por la dificultad que eso podía entrañar, debido a lo poco que se sabía de su vida clandestina y por lo que el mismo tema (herir la sensibilidad de las víctimas, sin ir más lejos) implicaba (Domínguez, 2003; Reinares, 2011).

Sin embargo, la ventaja de la comedia es que puede acometer tales hechos de forma libre, sin necesidad de atenerse exactamente a la realidad, aunque se beba referencialmente de ella. Además, la trama nos perfila una ETA en el momento de su mayor auge y otra venida a menos de una manera tan estrafalaria como satírica, lo que muestra la desacralización que se hace en este contexto, frente a aquellos que mostraban una ETA indestructible y a unos gudaris (soldado vasco, en euskera, apropiándose de ese valor simbólico nacionalista) tan heroicos como virtuosos en su forma de ser y en su abnegado sacrificio por la patria (veremos que no es así), a la que pretenden salvar del invasor español (Fernández Soldevilla, 2014, pp. 23-61). 
Aspectos tan recurrentes como la gastronomía, un lenguaje abertzale (Euskal Herria -para referirse a Euskadi- o la lucha -violencia terrorista), la identidad vasca de sus integrantes y, sobre todo, las relaciones personales, impregnan buena parte de esta radiografía que lleva a cabo de la vida clandestina de un comando (talde).

La primera escena del filme nos traslada a un auténtico piso franco en Bayona, en 1998 (austero, desnudo casi de muebles y con unos colchones en una habitación). Nada sabemos de los tres hombres y una mujer que están sentados a la mesa degustando una opípara comida. Entre ellos está un joven Martín y Artetxe (Ramón Barea), luego, un jefe de ETA. Solo cuando Artetxe le da, con cierta solemnidad, una pistola a Martín se escenifica que no son un grupo de amigos, sino un talde. La aparición de la policía (denominados txakurrak -perros, en euskera), llevará al arresto de todos menos Martín, que logrará huir "cobardemente", sin disparar un solo tiro.

La situación es muy cómica y surrealista, ya que Martín y Artetxe se encierran en el baño para comerse las páginas de unos cuadernos con información muy valiosa sobre ETA que no quieren que caiga en manos de las fuerzas del orden. Y Martín, tremendamente empachado por la comida, no puede llegar a tragarse los papeles.

Años después, Martín ha escalado grados en ETA y dirige su propio comando. Sin embargo, es muy ilustrativa la metáfora que se utiliza cuando están en el nuevo piso franco y toca un tema muy serio entre los integrantes del mismo, Alex (Gorka Otxoa), Ainara (Miren Ibarguren), ambos vascos, y Pernando (Julián López), de Chinchilla (Albacete): si alguien sabe cocinar. Los tres se miran y ninguno sabe y han de acabar comiendo unas croquetas calentadas en el microondas que les ha dado una vecina. Martín recuerda los buenos tiempos en ETA cuando "se comía de la hostia". Se trata de un guiño sardónico sobre la época buena de ETA, aunque parece presentarla con ironía, más como un club gastronómico que como una organización que pudiera perseguir un fin ideológico-revolucionario.

Un claro aspecto que se mostrará es el declive evidente de ETA en la composición de sus integrantes. Se nos presenta un comando formado por meros principiantes: el líder es Martín, que se siente acomplejado por ser riojano y que tuvo que huir a Venezuela. Hay además dos jóvenes vascos sin experiencia militar, Ainara, obsesionada con que está fichada por la policía, y Alex, que quiere irse con ella a Uruguay, que nunca han estado en primera línea y no saben nada de explosivos, y un manchego, Pernando, que ha euskaldunizado su nombre y apellido (Gartzia) para parecer vasco, seudoanarquista, antiguo albañil, obsesionado con ponerse un alias llamativo (Calleja, 2015, pp. 63-64) ${ }^{11}$, que cree que militar en la banda es la caña y que siente una atracción y fascinación sexual por las mujeres etarras. Sin embargo, tan variopinto grupo solo refleja una cosa: ETA es una sombra de lo que fue y eso le permite a Cobeaga llevar a cabo un retrato antirromántico y vulgarizado de su gris vida clandestina.

Mientras el talde espera la llamada, que no llega, de Artetxe ${ }^{12}$, han de pasar desapercibidos. De ahí que Martín deba decirle a la vecina, Lourdes, que son albañiles y comprometerse con otro vecino, Armando, a ver la final del Mundial si gana España.

Sin duda hay escenas muy logradas, como cuando Martín y Alex van a recoger a Pernando. Este expresará su orgullo de pertenecer a ETA, pero Martín le indicará que no lo es, que solo viene de apoyo. Y el otro considera que ha sido discriminado porque no es "vasco", como si ETA fuera una especie de familia mafiosa italiana. Por eso, acabarán discutiendo cuando Pernando saca a relucir que Martín es riojano y no vasco. Pero este es muy sensible con ese tema de su ascendencia y se enfada y zanja la cuestión con una analogía muy graciosa: “¿Los riojanos pueden jugar en el Athletic? ¿No? [En alusión a jugadores riojanos de ascendencia que sí lo han hecho] Pues, ya está". Y sentencia: "Si puedes jugar en el Athletic, también puedes ser de ETA".

Si en Ocho apellidos vascos se recoge, como el mismo título indicaba, que ser un auténtico vasco comportaba tener esa línea familiar euskaldún de ocho generaciones, aquí se añade otro ingrediente más, como es que la cultura deportiva vincula a la tradición del equipo del Athletic de Bilbao de solo fichar jugadores autóctonos. ${ }^{13}$

En todo caso, la escena se burla de una idiosincrasia futbolística muy particular sobre ese supuesto imperativo de ser vasco para poder militar en ETA. ${ }^{14}$ 
Otros momentos muy emblemáticos son cuando Martín discute sobre el ranquin en que se sitúa ETA en el marco de las tres organizaciones terroristas más importantes del mundo, casi como si estuviese hablando de un equipo de fútbol (entre el IRA, la más importante, y las Brigadas Rojas). O se perfila esa perversión de su imaginario histórico (el que recibió en una ikastola o escuela vasca), cuando se ponen a jugar al Trivial y se indigna porque su ideología antiespañola le impide aceptar o reconocer las respuestas que se dan en las tarjetas.

No obstante, la espera se convierte en una tortura (Ainara se obsesiona con acabar un puzle y se vuelve paranoica) y creen que se han olvidado de ellos, por lo que Martín se ve forzado a actuar. O lo que es lo mismo, a preparar por su cuenta un atentado. Y se encuentra con el problema de la financiación para adquirir los medios para lograrlo. Por tanto, tienen que hacer efectiva su tapadera y, cuando la vecina les pide que hagan la reforma del baño, Martín halla en esto la oportunidad de sufragarlo. La heroica luch a por la que este seudoanarquista, Pernando, se ha sumado a ETA es volver a un trabajo que no le gustaba, es el único que sabe del oficio.

Aunque sin ahondar en la cuestión, se alude al desprecio por los terroristas arrepentidos (Fernández Soldevilla, 2016, pp. 193-212; Terradillos, 2016) ${ }^{15}$ (de forma puntual) o la importancia del yihadismo (De la Corte, 2018) ${ }^{16}$, cuando Pernando, un auténtico ignorante, baja al piso de unos vecinos porque son marroquíes, y les pide, utilizando lo que él cree un lenguaje en clave (falafel=explosivo y Ramadán=atentado) material para hacer su propia bomba, jugando con el falso cliché de creer que todos los musulmanes son integrantes de Al-Qaeda, solo para evitar volver a ser albañil.

Asimismo, se nos presentan las tensiones emocionales que surgen en la cercanía de esta opresiva convivencia entre la joven pareja de Alex y Ainara. Ainara es la que ve con más nitidez su nefasta y patética situación y señala que la única acción que han llevado a cabo hasta ese instante ha sido cambiar una bañera por un plato de ducha. Enfatizando ese lado, previamente, a pesar de sus firmes convicciones antiespañolas, Martín se da cuenta de que su balcón es el único del edificio en que no cuelga una bandera rojigualda, apoyando al equipo de fútbol español, por lo que van a una tienda de chinos a adquirir una y lo que adquieren es un toldo.

Momento gracioso cuando lo despliegan en la casa, atravesándola de parte de parte, y, para colmo, se dan cuenta de que lleva el motivo del toro Osborne.

La deriva de la historia se vuelve cada vez más ácida y peripatética ya que los integrantes del talde se convierten, a partir de ahí, en exitosos albañiles. A cambio, no solo logran comprar una partida de petardos que Pernando debe convertir en una bomba... el sonoro atentado que reivindica Martín en nombre de ETA se queda, en la noche de celebración de que España va a la final, en una explosión de fuegos artificiales. Y algunos de los viandantes no solo creen que es una broma, sino que se lo arrogan a Al-Qaeda, viendo, así, que ETA ya ha perdido su poder intimidatorio en la sociedad.

Así mismo, resultan chocantes los consejos que pretende dar Martin a la joven pareja, Alex y Ainara, cuando esta decide irse, y para ello utiliza todo un argot político que acaba por molestar a la chica, al identificarla con España en sus comparaciones. Y la conversación entre ambos es muy intensa, una sátira política muy incisiva que hace un resumen, después de todo, de los hitos de la historia vasca en la democracia (De Pablo, De la Granja, Rubio, 2011; Montero, 2013), reduciendo el supuesto conflicto político en una historia de amor fallida...

En la parte final, todos y cada uno de los personajes se caracterizan por mostrar aspectos totalmente inesperados. Martín, por primera vez, manifestará su verdadero valor, pero no en lo que uno podría esperar, sino con quien más humillaciones le ha hecho, Artetxe. La pareja joven de enamorados decidirá crear su propio comando itinerante, dándole un sentido irónico totalmente diferente, en otras palabras, independizarse e irse a vivir juntos, rompiendo esa barrera emocional que les ha mantenido separados ante la prevalencia de la causa y viendo que, sin ella, pueden ser realmente felices. Y, finalmente, el único que ha 
militado en ETA por la falsa seducción del heroísmo peliculero que encarna, Pernando, acaba aceptando la fábula de creer que sigue en la lucha con su trabajo de albañil, convirtiéndolo en un próspero negocio.

"El guion de Diego San José parte de la premisa de que, detrás de todo lo humano, late siempre una fragilidad potencialmente ridícula, pero también potencialmente desoladora" (Costa, 2017). Además, no solo se mofa de una ETA aguerrida y fiera, de profundos ideales y capaz de todo, sino que también nos muestra esa faceta tan humana en la que nos acabamos adaptando a las circunstancias, construimos nuestras propias idiosincrasias y que, muchas veces, ciertos supuestos ideales (como militar en la banda terrorista) no sacan lo mejor de nosotros, sino que nos acobardan y nos reprimen emocionalmente.

\section{CONCLUSIÓN}

La apuesta por la comedia cinematográfica a la hora de retratar a la izquierda abertzale (en Ocho apellidos vascos) y a ETA (Negociador y Fe de etarras) ha respondido y se explica gracias a un nuevo contexto político y social. El primer intento fallido de los años 90 dejó huérfano un territorio que, sin duda, de haber prosperado, no habría podido cambiar lo sucedido, pero sí habría encarado de otra manera el devenir de la violencia de ETA. Está claro que el reírnos con agudeza de aquellos que provocan el miedo y el terror resulta muy terapéutico, y es la mejor manera de exorcizar su feroz dramatismo y desautorizar su fanatismo.

Sería, precisamente, este tándem formado por los guionistas Borja Cobeaga y Diego San José los que abririan fuego. El desnudar ciertos aspectos de la sociedad vasca, que ellos conocían tan bien (gracias a esa labor desarrollada en el programa de humor televisivo Vaya semanita), y criticar ciertas idiosincrasias, a través del uso de clichés, para mostrar el rostro cómico de ciertos estereotipos culturales, resultaría tremendamente atractivo y fue muy bien acogido por el público. Claro que no solo debemos fijar en sus aspectos comerciales, para el destacado caso de Ocho apellidos vascos, sino en su implicación de liberación emocional. Era necesario que volviera la risa, frente a la tragedia, mostrar que portamos aspectos muy divertidos en nuestras identidades cuando las representamos de forma exagerada y poder hacerlo sin temor. Su fin no era humillar, sino mostrar como somos seres humanos con nuestras virtudes y defectos. Y explorando estas dos facetas Cobeaga y San José iban a desarrollar su trilogía satírica.

El tratamiento que van a llevar a cabo sobre el mundo de ETA cobrará, así mismo, en Negociador unos tintes muy ácidos, tanto en el modo en el que se muestra el uso de un lenguaje político que evidencia la dificultad a la hora de entendernos, como en esa fría conceptualización de la realidad tan oscurantista y confusa que solo ha facilitado a los violentos sus actuaciones (los atentados). Por eso, Fe de etarras completa con acierto esta visión, equilibrando bien seriedad y comedia, que nos revela el universo clandestino de ETA en modo de comedia negra y desidealizada, con unos personajes que no solo se acabarán adaptando a las circunstancias, sino que serán mucho más felices cuando se les libere de la causa terrorista que perseguían.

En efecto, el final de ETA no solo ha venido ligado a su derrota y posterior disolución, sino acompañado de forma positiva por un nuevo impulso artístico. Si bien es verdad que la acogida de estos filmes fue dispar y los dos centrados más en ETA fueron peor recibidos, no se debe obviar la ruptura tan importante que se hizo con la introducción de un género cómico que parecía encajar tan poco con el drama vasco, y que desacraliza todo ese lenguaje constituido para defender los elementos del mito del conflicto vasco.

Tal y como sintetiza de forma tan clara Calleja: "De icono de la resistencia del pueblo vasco, de ídolo de los jóvenes vascos en su lucha por la Euskadi independiente y libre, ETA ha pasado a dar risa, a recibir críticas, ironías y mofas en las redes sociales y en el cine" (2015, p. 67).

En otras palabras, ya no provoca un temor reverencial y retraído, sino un sentimiento de rechazo frontal y valiente. Bien es verdad que queda todavía mucho camino que recorrer de cara a la superación, asimilación y aprendizaje sobre lo sucedido y el atento cuidado de la dignidad de las víctimas, pero está claro que el séptimo arte se ha implicado en hacerlo en la dirección correcta. 


\section{ANEXO}

\begin{tabular}{|l|l|l|l|l|}
\hline Películas & Director & Género & Temática & Espectadores \\
\hline $\begin{array}{l}\text { Cómo levantar 1.000 } \\
\text { kilos (1991) }\end{array}$ & $\begin{array}{l}\text { Antonio } \\
\text { Hernández }\end{array}$ & Comedia & ETA & 1.533 \\
\hline $\begin{array}{l}\text { Ocho apellidos } \\
\text { vascos (2014) }\end{array}$ & $\begin{array}{l}\text { Emilio } \\
\text { Martínez } \\
\text { Lázaro }\end{array}$ & Comedia & $\begin{array}{l}\text { Izquierda } \\
\text { abertzale }\end{array}$ & 9.397 .647 \\
\hline Aupa Josu (2014) & $\begin{array}{l}\text { Borja } \\
\text { Cobeaga }\end{array}$ & Comedia & ETA & - \\
\hline $\begin{array}{l}\text { Negociador (2014) } \\
\text { Cuerpo de élite } \\
\text { (2016) }\end{array}$ & $\begin{array}{l}\text { Borja } \\
\text { Cobeaga } \\
\text { Mazón }\end{array}$ & Comedia & ETA & 33.961 \\
\hline Fe de Etarras (2017) & $\begin{array}{l}\text { Borja } \\
\text { Cobeaga }\end{array}$ & Comedia & ETA & $\begin{array}{l}\text { Cuerpos } \\
\text { policiales }\end{array}$ \\
\hline
\end{tabular}

\section{REFERENCIAS}

Aizpeolea, Luis R. (10 de junio de 2007). Así fue el diálogo con ETA. El País. Recuperado de http://elpais.com Aizpeolea, Luís R (20 de octubre de 2011). ETA pone fin a 43 años de terror. El País. Recuperado de http://elpais.com Arregi, Joseba (2015). El terror de ETA. Madrid: Tecnos.

Barrenetxea, Igor (2003). La trilogía vasca de Imanol Uribe: Una mirada al nacionalismo radical vasco a través del cine. Ikusgaiak, 6, 77-101.

Barrenetxea, Igor y Viadero, Gabriela (2017). El fin de ETA y Ocho apellidos vascos (2014), de Emilio Martínez Lázaro. Aportes, 94, 243-269.

Belategui, Oskar (22 de septiembre de 2017). Entrevista a Borja Cobeaga. El Diario Vasco. Recuperado de http://w ww.diariovasco.com

Calvo Soler, Raúl (2009). La negociación con ETA: entre la confusión y los prejuicios. Barcelona: Gedisa.

Calleja, José María (2015). De icono de los vascos en los sesenta a caricatura de las redes sociales hoy. Los ídolos de ETA: de dar miedo a dar risa. CIC. Cuadernos de Información y Comunicación, 20, 57-68.

Carcajosa Virino, Concepción (2010). La representación del fenómeno terrorista en la televisión contemporánea en España: del tabú a la ficción y el humor. En Juan Carlos Ibáñez y Francesca Anania (Coords.), Memoria histórica e identidad en cine y televisión (pp. 183-210). Sevilla-Zamora: Comunicación Social.

Castells, Luis, y Rivera, Antonio (2015). Las víctimas del victimismo construido a las víctimas reales. En Fernando Molina y José A. Pérez (Eds.). El peso de la identidad. Mitos y ritos de la historia vasca (pp. 265-305). Madrid: Marcial Pons.

Costa, Jordi (12 de octubre de 2017). En ETA se comía la hostia. El País. Recuperado de http://elpais.com 
De la Corte Ibáñez, Luis (2018). La yihad de Europa: desarrollo e impacto del terrorismo yihadista en los países de la Unión Europea (1944-2017). Informe del Centro Memorial de las Victimas del Terrorismo, 4, 1-76.

De Pablo, Santiago, De la Granja, José Luís, y Rubio, Coro (2011). Breve historia de Euskadi: de los Fueros a la Autonomia. Madrid: Debate.

De Pablo, Santiago (2017). Creadores de sombras. ETA y el nacionalismo vasco a través del cine. Madrid: Tecnos.

Domínguez, Florencio (2003). Dentro de ETA. Madrid: Punto de Lectura.

Domínguez, Florencio (2017). Las claves de la derrota de ETA. Informe del Centro Memorial de las Victimas del terrorismo, 3, 1-63.

Fernández Soldevilla, Gaizka, y López Romo, Raúl (2012). Sangre, votos, manifestaciones: ETA y el nacionalismo vasco radical 1958-2011. Madrid: Tecnos.

Fernández Soldevilla, Gaizka (2014). Gudaris: El imaginario bélico de ETA y su opción por la violencia. En Daniel Macías y Fernando Puell (Eds.), David contra Goliat: Guerra y asimetría en la Edad Contemporánea (pp. 23-61). Madrid: Instituto Universitario General Gutiérrez Mellado-UNED.

Fernández Soldevilla, Gaizka (2015). Mitos que matan. La narrativa del conflicto vasco. Ayer, 98, 213-240.

Fernández Soldevilla, Gaizka (2016). La voluntad del gudari. Génesis y metástasis de la violencia de ETA. Madrid: Tecnos.

Ferro, Marc (1995). Historia contemporánea y cine. Barcelona: Ariel.

FilmAffinity. Página web. https://www.filmaffinity.com/es [consultado el 9-2-2019]

García, Rocío (22 de septiembre de 2014). Borja Cobeaga: En el País Vasco todavía hay mucho que contar. El País. Recuperado de http://elpais.com

Koch, Tommaso (17 de mayo de 2017). Fe de Etarras, una comedia alocada sobre ETA, será la segunda película española de Netflix. El País. Recuperado de http://elpais.com

López Romo, Raúl (2015). Informe Foronda: los efectos del terrorismo en la sociedad vasca (1968-2010). Madrid: Catarata.

Martínez Álvarez, Josefina (2017). Relatos del sufrimiento: el reconocimiento de las víctimas en las películas sobre el terrorismo. Cuadernos del Centro Memorial de las Victimas del Terrorismo, 4, 98-120.

Mate, Reyes (2008). Justicia de las victimas. Terrorismo, memoria, reconciliación. Barcelona: Anthropos.

ICAA-MECD (Instituto de la Cinematografía y de las Artes Audiovisuales-Ministerio de Educación, Cultura y Deporte). Página web. http://infoicaa.mecd.es [consultado el 9-2-2019]

Molina, Fernando (2015). El conflicto vasco. Relatos de memoria, historia y nación. En Fernando Molina y José A. Pérez (Eds.), El peso de la identidad. Mitos y ritos de la historia vasca (pp. 181-223). Madrid: Marcial Pons.

Montero, Manuel (2013). Historia del País Vasco. San Sebastián-Donostia: Txertoa.

Reinares, Fernando (2011). Patriotas de la muerte. Madrid: Taurus.

Rodríguez, María Pilar (Ed.) (2015). Imágenes de la memoria. Victimas del dolor y la violencia terrorista. Madrid: Biblioteca Nueva.

Roldán, Carlos (2001). Una apuesta suicida: ETA en el cine de Euskadi. Ikusgaiak, 5, 181-205.

Rosenstone, Robert A. (2014). La historia en el cine: el cine sobre la historia. Madrid: Rialp.

San José, Diego (2008). En ocasiones... bebo mosto. El caso de Vaya Semanita. En Pedro Sangro y Alejandro Salgado (Eds.), El entretenimiento en TV: guion y creación de formatos de humor en España (pp. 239-250). Barcelona: Laertes.

Sordo Estella, Luis Miguel (2017). Promesas y mentiras: las negociaciones entre ETA y los Gobiernos de España (1976-2006). Madrid: Tecnos.

Terradillos, Ana (2016). Vivir después de matar. Madrid: La Esfera de los Libros. 


\section{Notas}

1 Está compuesta por los filmes El proceso de Burgos (1979), La fuga de Segovia (1981) y La muerte de Mikel (1984).

2 De hecho, abundan esta clase de comedias satíricas y corrosivas de humor negro, como ejemplos recientes destacar: Mein Führer (2007), de Dani Levy, Four Lions (2010), de Chris Morris, El dictador (2012), de Larry Charles, The Interview (2014), de Evan Golberg y Seth Rogen, La muerte de Stalin (2017), de Armando Iannuci y Bye Germani (2017), de Sam Garbarski.

3 Anterior a este, el filme La Blanca Paloma (1989), de Juan Miñón, también se recurriría a ese mismo contraste, entre lo andaluz y lo vasco, ambientada en el Bilbao industrial, si bien con escaso éxito.

4 Fue un fenómeno que se inició en los años 90, referido a los actos de violencia callejera que protagonizaron jóvenes simpatizantes de la izquierda abertzale (radicales vascos) en las grandes ciudades vascas quemando contenedores y enfrentándose a la policía, denominado terrorismo de baja intensidad.

5 Porque no toda Euskadi está integrada por paisajes de postal, pueblecitos rurales o pesqueros, sino que también hay grandes ciudades y zonas industriales.

6 Debido a las polémicas suscitadas respecto a negociar con terroristas y su efecto en la opinión pública.

7 Esta diferencia es importante. Para ETA y la izquierda abertzale el mito del conflicto que existe entre España-Euskadi de raíces históricas justifica el terrorismo y, por consiguiente, es una confrontación entre dos realidades opuestas, vascosespañoles. Y se considera que España mantiene ocupada y secuestrada la voluntad de los vascos. Para los partidos demócratas vascos, en cambio, nada justifica su violencia y es ETA quien impone, con su totalitarismo, sus condiciones.

8 De hecho, empezó a verse que en los periodos de tregua la izquierda abertzale recibía más votos que en los momentos en los que ETA la rompía.

9 El mismo director consideró la polémica negativa señalando: "El humor que antes era motivo de unión entre vascos y españoles ahora es ofensa".

10 De la expresión $F e$ de erratas, que es lista de errores encontradas en un libro, se pasa a Fe de etarras, en una aliteración irónica en el que se puede dar la comparación de errata=etarra.

11 Eran algo muy común en ETA. Y señala este autor: "Los alias son una forma de popularizar, de idolatrar a base de costumbrismo y espíritu de secta, a unos asesinos que se quieren presentar como jatorras” -simpático en euskera- (Calleja, 2015, p. 64).

12 Tal vez sea lo único incongruente del filme, ya que tras su detención, en la primera secuencia, no se explica cómo ha conseguido ser puesto en libertad y rara vez se solían reincorporar de nuevo a la banda (salvo excepción como Josu Ternera), tras haber cumplido sus años de cárcel.

13 A saber, nacidos en Euskadi, Navarra e Iparralde (Francia), o bien, haber sido formados en las categorías inferiores del club o de otros clubs vascos (lo que implica que hay jugadores no vascos que pueden ser fichados).

14 Si bien, hubo activistas de ETA que no eran vascos, y en otros casos, lo eran de segunda generación.

15 Los arrepentidos son aquellos que se acogieron a la vía Nanclares y rompieron o fueron expulsados de ETA, por lo tanto, eran considerados traidores a la causa.

16 Pues, en el efecto de los atentados en Europa estaba muy presente en aquellos años tras lo ocurrido en Madrid, Londres y París.

17 Fracaso relativo, pues el filme no estaba destinada a los cines, sino para la plataforma digital Netflix.

\section{BY-NC-SA}

